\title{
MONITORING WIND TURBINE USING WI-FI NETWORK FOR RELIABLE COMMUNICATION
}

\author{
Harikrishnan.R ${ }^{1}$, Shajna S. Hameed ${ }^{2}$, S.SivaKumar ${ }^{3}$ \\ ${ }^{1}$ Post Graduate Student of Vel Tech Dr.RR \& Dr.SR Technical University, Avadi, Chennai \\ ${ }^{2}$ Post Graduate Student of Vel Tech Dr.RR \& Dr.SR Technical University, Avadi, Chennai \\ ${ }^{3}$ Asst.Proffessor of Vel Tech Dr.RR \& Dr.SR Technical University, Avadi, Chennai
}

\begin{abstract}
Wind Energy is one of the most important features in the smart gird is to integrate the state-of-the-art communication technologies to increase the electric generation. In offshore wind farms, data communications would rely on wireless techniques. The wireless communication technology has several advantages over the wires or meter counterpart. However, the impact of atmospheric turbulence on wired must be well understood first. In this project, the performance of wireless links subject to weak influence in generator, turbine is monitored. Tolerance of the wireless communication network will be 2.5GHz. In Proposed system Wi-Fi Network forms perfect real time monitoring health of wind turbine.
\end{abstract}

Keywords-Wind turbine, Energy conversation, Wireless communication, Conditional Monitoring, Vibration Sensor, MEMS, Fault Diagnosis

\section{INTRODUCTION}

The core objectives of this proposed wireless health monitoring system are to detect the present health condition of the machine, to prevent failures caused by mechanical faults, to improve the power quality before the problem is corrected, to predict the severity level of fault, and to estimate the useful life of the machine. The use of this type of health monitoring system helps to reduce the failure frequency and amount of downtime, maximize the utilization of the wind turbine, and minimize the maintenance overhead and cost due to production lost. Moreover, under the wireless sensor network system, there is no need to install wiring for data collecting and monitoring, thus eliminating the cost of installation and maintenance that would be required by communication cables.

Wind power is the fastest growing energy resource. Its capacity has exceeded up to $120 \mathrm{GW}$. Wind power is used to improve the quantity and quality of generation. To overcome the failure of wind turbines, many types of failures are reviewed. Wind turbine generators produce some power which is complex electromechanical systems.

Health monitoring system collect data from wind turbine components of generator, gear box, the shaft and the yaw system. It is used to reduce the maintenance cost and downtime. But it increases the energy consumption and components service. It has few sensors. To correct the structural condition and to enhance the efficiency and prevent the failures, the wind turbine producers and operators worked hard. But now the accident happens. Fig.1. shows the insufficient number of monitoring system of wind turbine.

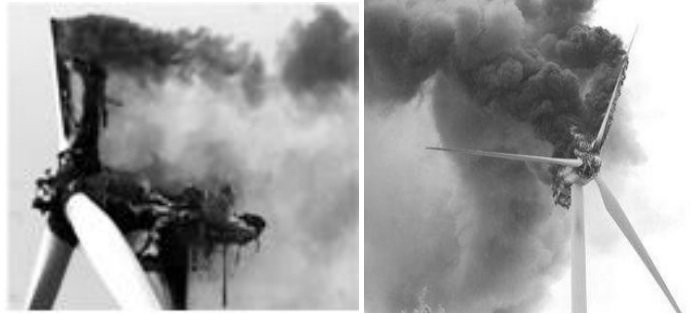

Fig-.1. Catastrophic Failure of a Wind turbine due to Lack of Proper Monitoring System

\section{WIND TURBINE FAULTS}

\subsection{Fault Detection and Failures of Wind Turbine}

Though the wind turbine has thousands of components, it results to lot of different failures. Failures occur frequently. This results to economic loss. This is caused by downtime of particular component. Fig.1.2 shows the annual average downtime of wind turbine subassemblies based on LWK survey of about 2000 wind turbine for 11years.

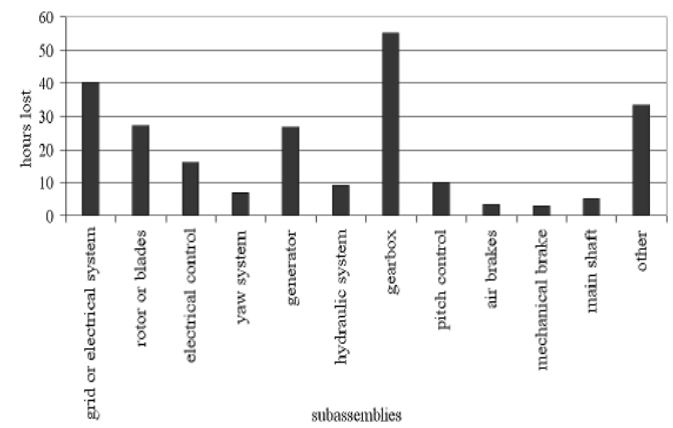

Fig-2 Annual Hours Lost Caused by Wind Turbine Subassemblies 
Figure 2, shows that gearbox; grid or electrical system, rotor blade, and generator are ranked the fourth on annual average downtime. Malfunction caused the high downtime. So it received the highest priority. Commercially this system should paid more attention to subassemblies. This system focused electrical faults occurring in generator, grid or electrical system, and the converter. However, most monitoring systems focus more on detecting [13-17].

\subsection{Two Stage Gear Box}

At present the detection and monitoring system consists of temperature analysis, lubrication oil level measurement and strain level. These are helpful in detecting mechanical failures but not suitable for detecting mechanical faults occurring in gear system and generator. For better sensing of mechanical faults the new vibration based monitoring system is proposed here in figure. 3 where the fault occurs either in blades, bearings shaft or gearbox will affect the generator of wind turbine. This will affect the rotor and stator of turbine which directly affects the production of the generator.

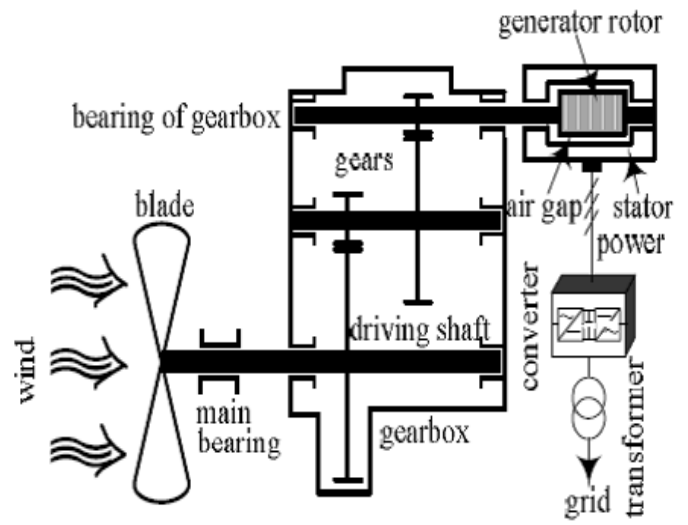

Fig.-3. Diagram of a Wind Turbine with a Two-stage Gearbox

The continuous imbalance in this condition will result to failure of the turbine. In order to avoid the electrical faults many methods have been undergone and produce the effective result but in order to avoid the mechanical fault this is the effective way to approach the fault monitoring. Here we use MEMS based accelerometer sensor is proposed to monitor the mechanical faults detected in the wind turbine.

\subsection{Equations}

In the first mode of operation of a wind turbine, i.e., for wind speeds less than rated speed, the pitch angle is fixed and the electrical torque is used to control the rotor speed to make it track the optimal tip-speed ratio. We can write the rotor speed equation in standard affine form as follows:

$$
\dot{\Omega}=f\left(\Omega, V_{w}\right)+g T_{g}
$$

where $T_{g}$ is the input and

$$
f\left(\Omega, V_{w}\right)=\frac{\frac{1}{2} \rho \pi R^{3} \frac{C_{p}(\hat{\lambda})}{2}\left(V_{w}\right)^{2}-K_{t} \Omega}{\left(J_{R}+J_{G}\right)}, g=\frac{-1}{\left(J_{R}+J_{G}\right)}
$$

where $g$ is constant. Using the RBF NN, we train a nonlinear approximator so that

$$
\frac{f\left(\Omega, V_{w}\right)}{g}=\emptyset\left(\Omega, V_{w}\right) w+d\left(\Omega, V_{w}\right)
$$

where $\left|d\left(\Omega, V_{w}\right)\right| \leq d_{\max }$ is the NN approximation error. Now we define the tracking error, $e$, such that

$$
e=\Omega-\Omega_{\mathrm{opt}}\left(V_{w}\right)
$$

where $\Omega_{\text {opt }}$ is the optimal rotor speed, and is given by the following relation:

$$
\Omega_{\mathrm{opt}}\left(V_{w}\right)=\frac{\lambda_{\mathrm{opt}} V_{w}}{R} .
$$

\subsection{Machine Vibration Analysis}

Vibration analysis is a proven and effective technology being used in condition monitoring. For the measurement of vibration, figure. 4 shows different vibration transducers are applied, according to the frequency range. Vibration measurement is commonly done in the gearbox, turbines, bearings, and shaft. For wind turbine application, the measurement is usually done at critical locations where the load condition is at maximum, for example, wheels and bearings of the gearbox, the main shaft of turbine, and bearings of the generator.

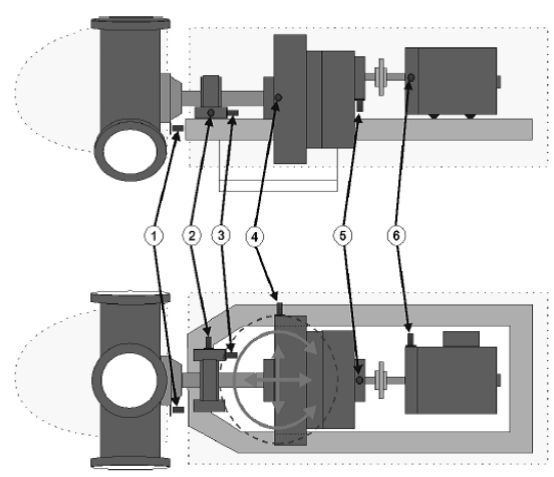

Fig-.4. Common Sensor Configurations for Horizontal Axis Wind Turbine

\subsection{Methodology}

$>\quad$ This fault monitoring system is based on the study of vibration analysis.

$>$ The vibration produced from the wind turbines are sensed by using ADXL330 MEMS Accelerometer.

$>$ The vibrations under different load conditions like on load, no load and abnormal conditions are observed and the corresponding voltage produced is added as a reference value to PIC. 
$>\quad$ The PIC an advanced 8-bit microcontroller, which is used to analyze the data obtained from wind turbine via MEMS.

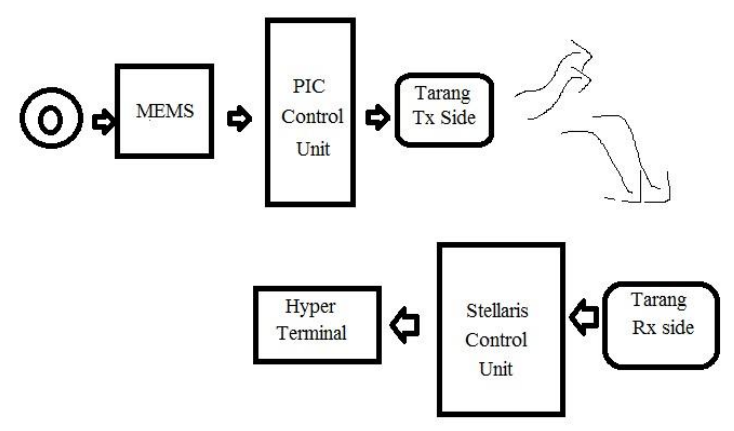

Fig-.5. Methodology

$>$ The analyzed output data is sent to Zigbee transmitter, the Zigbee transmitter and STELLARIS microcontroller are interfaced by using $\max 232$ to convert the output to CMOS from TTL.

$>\quad$ The Zigbee receiver, which is placed in the control station receives the signal and gives it to STELLARIS unit to display the operating condition of the wind turbine.

$>$ This system figure.5 ensures the continuous monitoring of the wind turbine and reduces the downtime and losses due to damage.

\section{SIMULATION STUDY}

\subsection{Software and Hardware}

$\mathrm{C}$ compiler is a useful tool that helps the user for initializing peripherals and writing code for MSP430 c-Controller. Different peripherals options/settings are presented in form of Graphical User Interface (GUI). It creates the basic layout of the code that include different interrupt service routines, Initialization parameters for timers, interrupts and other device peripherals etc., A large Microcontroller family provides user, the flexibility to select the chip which fulfills the requirement optimally. The devices which have large features are more costly. So, from Economical point of view, select the device which only has those features that the design requires.

Motor vibration measured by MEMS accelerometer with help of Hyper Terminal software. MEMS sensor need 5V supply it is taken in MSP430 Launchpad. The Hyper Terminal measured the signal by using Energia software ( $\mathrm{C}$ compiler).

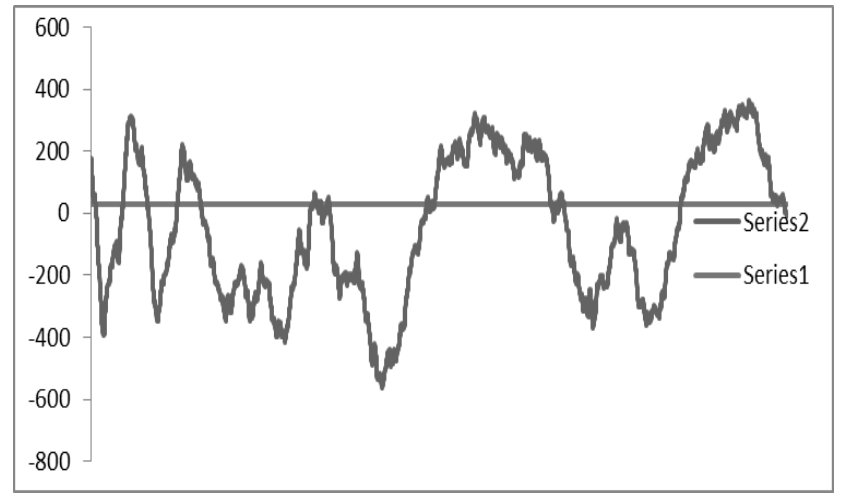

Fig 6 AC Induction Motor No load (Analog)

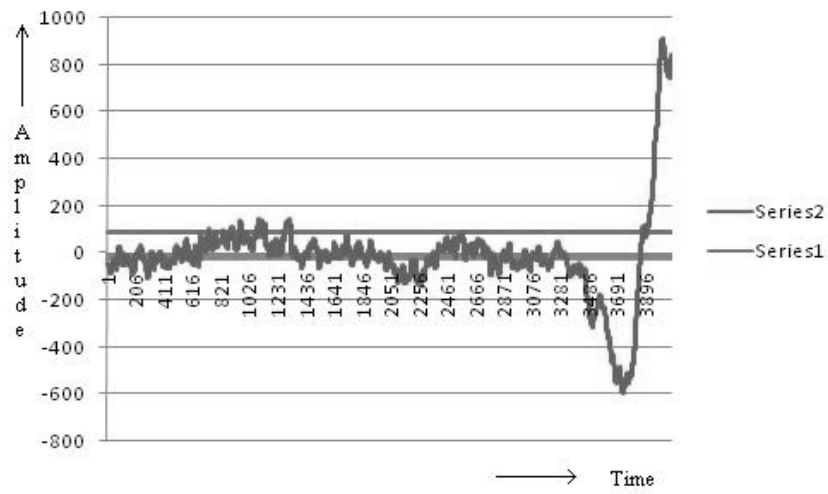

Fig.7. AC Induction Motor 50\% load (Analog)

Both figure $6 \& 7$ shows the output simulated with two conditions as follows, with load and without load optimally. The devices which have large features are more costly. So, from Economical point of view, select the device which only has those features that the design requires.

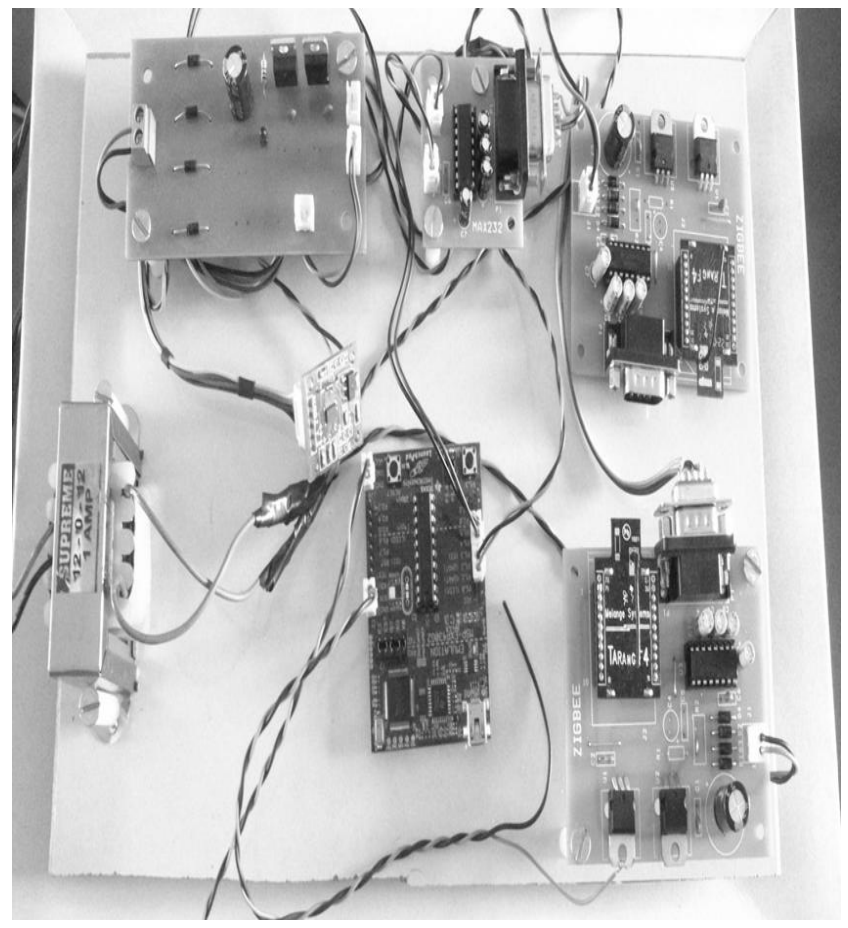

Fig-8 Hardware working kit 


\section{CONCLUSIONS}

The mechanical failure is the most serious problem faced in the wind turbines. More sensitive regions like gears and generators are more vulnerable to faults which are the major reasons to affect the production of wind turbine. The machine health monitoring which is proposed here is more important thing that to discussed. There are many methods to identify the faults but they are not more acquired or more confident method the fault identification through the vibration is the effective way to identify the fault in the mechanical devices. and the wireless technique used here helps us to analyst and measure the abnormalities of the machine. MEMS accelerometer which is low expense sensor, smaller in size and weights which is more accessible and it consumes only less power. These are the important segments of the fault monitoring system. By implementing this practically we reduce the accuracy of fault in the moving objects like gear, generator and shaft. And we can increase the production rate through eliminating these faults. The fault monitoring and control will reduce the level of severity.

This study presents an excellent wireless health monitoring for wind turbine systems to detect the severity level of mechanical fault conditions of the windmill. Moreover, a new 3 axis sensor is proposed to monitor the wind turbine output during imbalance conditions. The major contributions of this dissertation are:

Develop and implement a Zigbee based wireless sensor network for a health monitoring which will be able to detect mechanical fault conditions based on the vibration signature. Propose and validate vibration based detection techniques to predict the level of fault severity and be able to estimate the usable life of the equipment.

To reduce the downtime and manual procedures by continues monitoring of wind turbine operations.

Developing a new predictive monitoring system instead of protective system to ensure the Good condition of wind turbines, to develop a wireless monitoring system to overcome the drawbacks of wired networks.

The overall cost of the monitoring system get reduced due to no usage of wired conductors for signal transmission, the low cost microcontrollers and low power consumption equipment's are used.

\section{REFERENCES}

[1] $20 \%$ wind energy by 2030 : increasing wind energy's contribution to U.S. electricity supply," United States Department of Energy, Rep. DOE/GO-102008-2567, Jul. 2008.

[2] J. Ribrant and L. M. Bertling, "Survey of failures in wind power systems with focus on swedish wind power plants during 1997-2005", IEEE Trans. Energy Conversion, vol. 22, no. 1, pp. 167-173, Mar. 2007.

[3] Y. Amirat, M. E. H. Benbouzid, B. Bensaker, and R. Wamkeue, "Condition monitoring and fault diagnosis in wind energy conversion systems: a review", in
Proc. 2007 IEEE International Electric Machines and Drives Conference, vol. 2, May 2007, pp. 1434-1439.

[4] M. R. Wilkinson, F. Spinato, and P. J. Tavner, "Condition monitoring of generators and other subassemblies in wind turbine drive trains", in Proc. 2007 IEEE International Symposium on Diagnostics for Electric Machines, Power Electronics and Drives, Sep. 2007, pp. 388-392.

[5] C. A. Walford, "Wind turbine reliability: understanding and minimizing wind turbine operation and maintenance costs," Sandia National Laboratories, Rep. SAND2006-1100, Mar. 2006.

[6] C. Hatch, "Improved wind turbine condition monitoring using acceleration enveloping," Orbit, pp. 58-61, 2004.

[7] R. W. Hyers, J. G. McGowan, K. L. Sullivan, J. F. Manwell, and B.C. Syrett, "Condition monitoring and prognosis of utility scale wind turbines," Energy Materials, vol. 1, no. 3. pp. 187- 203, Sep. 2006.

[8] M. R. Wilkinson, F. Spianto, M. Knowles, and P. J. Tavner,"Towards the zero maintenance wind turbine," in Proc. 41st International Universities Power Engineering Conference, vol. 1, 2006, pp.74-78.

[9] D. McMillan and G. W. Ault, "Quantification of condition monitoring benefit for offshore wind turbines," Wind Engineering, vol. 31, no. 4, pp. 267285, May 2007.

[10] P.J. Tavner, G.J.W. van Bussel and F. Spinato, "Machine and converter reliabilities in wind turbines," The 3rd IET International Conference on Power Electronics, Machines and Drives, Dublin, Ireland, pp. 127-130, March 2006.

[11] L. M. Popa, B.-B. Jensen, E. Ritchie, and I. Boldea, "Condition monitoring of wind generators," in Proc. IAS Annu. Meeting, vol. 3, 2003, pp. 1839-1846.

[12] F. D. Bianchi, H. D. Battista, and R. J. Mantz, Wind Turbine Control Systems. New York: SpringerVerlag, 2007, pp. 159-188.

[13] P. Caselitz, W. Kleinkauf, T. Kruger, J. Petschenka, M. Reichardt, and K. Storzel, "Reduction of Fatigue loads on wind energy converters by advanced control methods," in Proc. Eur. Wind Energy Conf., Oct. 1997, pp. 555-558.

\section{BIOGRAPHIES}

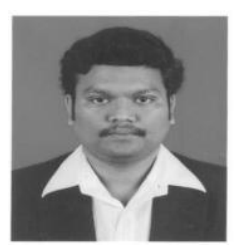

R.HARIKRISHNAN received the B.E. degree in electronics and communication engineering from the Sri Ramanujar Engineering College, Kolapakkam Anna University, Chennai, India, in 2007. Currently doing M.Tech. in Embedded system Technolgies in Vel tech Dr.RR \& Dr.SR Technical University, Avadi, Chennai, IndiaCurrently he is carrying his research in the field of Wind Engergy, Wifi Network, RF Technology etc., 
SHAJNA S.HAMEED received the B.E. degree in electronics and communication engineering from the Marthandam College of Engineering and Technology, Kanyakumari, India, in 2011. Currently doing M.Tech. in Embedded system Technolgies in Vel tech Dr.RR \& Dr. SR Technical University, Avadi, Chennai, IndiaCurrently she is carrying his research in the field of Wireless Communication, Embedded system, Mobile communication etc.,

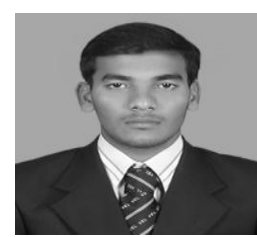

S.SIVAKUMAR received the M.E. in Embedded system Technolgy and Working as Assistant Professor in Vel tech Dr.RR \& Dr. SR Technical University, Avadi, Chennai, IndiaCurrently he is carrying his PhD in power system based renewable energy resources related to power quality etc., 